\title{
Response to: Cardinal L, da Silva TR, Andujar ALF, Gribel BF, Dominguez GC, Janakiraman N. Evaluation of the three-dimensional (3D) position of cervical vertebrae in individuals with unilateral posterior crossbite. Clin Oral Investig. 2021 Jul 13. doi: 10.1007/ s00784-021-04020-5
}

\author{
Jiří Šedý 1,2
}

Received: 2 August 2021 / Accepted: 17 October 2021 / Published online: 27 October 2021

(c) The Author(s), under exclusive licence to Springer-Verlag GmbH Germany, part of Springer Nature 2021

Sir,

Cardinal et al. [1] recently published a very nice paper showing a positive correlation between transverse occlusal changes and positional deviations of the cervical vertebrae. It is a very nice, systematic and well-written study, which will undoubtedly have significant impact on our understanding of the relations of posture and malocclusion. However, in discussion, they misinterpreted a fundamental study of D'Attilio et al. [2] stating: "Composite interference was created on one of the molars of each rat in the test group. They observed that all rats in the test group developed scoliotic curvature. After the removal of composite, $83 \%$ of the rats in the test group had their curvature restored." [1]. D'Attilio et al. [2] did not removed the composite but prepared second composite bite pad on the other side. Although it could be interpreted as a detail, in clinical dentistry, it would be much different if we remove the interference, which has an ability of relieving all symptoms or form another one on the other side, which would (except other problems) increase the vertical dimension of occlusion with significant risk of posteriorotation of the mandible, posteriorotation of the head and increasing lordosis of the cervical spine, with a possible consequence of the development of cervicogenic headache [3]. The paper of D'Attilio et al. [2] should be challenged in this perspective, because D'Attilio et al. [2] did not analyse

Jiři Šedý

jirisedy@jirisedy.cz

1 Institute of Dentistry and Oral Sciences, Faculty of Medicine and Dentistry, Palacky University, Olomouc, Czech Republic

2 Department of Anatomy, Second Faculty of Medicine, Charles University, Plzeňská 130/221, 15006 Prague 5, Czech Republic their results in sagittal plane-if they would, they might have found significant impairment (enhancement) of lordoses and kyphoses throughout whole spine and possibly would not conclude their study as "spinal column returned to normal condition [...] when the balance of in occlusal function was restored". In sagittal plane, it was not restored-it was impaired significantly, with a risk of clinically very important consequences_-but D'Attilio et al. [2] did not analyse them.

\section{Declarations}

Ethical committee N/A

Conflict of interest The author declares no competing interests.

\section{References}

1. Cardinal L, da Silva TR, Andujar ALF, Gribel BF, Dominguez GC, Janakiraman N (2021) Evaluation of the three-dimensional (3D) position of cervical vertebrae in individuals with unilateral posterior crossbite. Clin Oral Investig. https://doi.org/10.1007/ s00784-021-04020-5

2. D'Attilio M, Filippi MR, Femminella B, Festa F, Tecco S (2005) The influence of an experimentally-induced malocclusion on vertebral alignment in rats: a controlled pilot study. Cranio 23(2): 119-129. https://www.tandfonline.com/doi/abs/10.1179/crn.2005.017

3. Bogduk N, Govind J (2009) Cervicogenic headache: an assessment of the evidence on clinical diagnosis, invasive tests, and treatment. Lancet Neurol 8: 959-968. https://www.thelancet.com/ journals/laneur/article/PIIS1474-4422(09)70209-1/fulltext

Publisher's note Springer Nature remains neutral with regard to jurisdictional claims in published maps and institutional affiliations. 